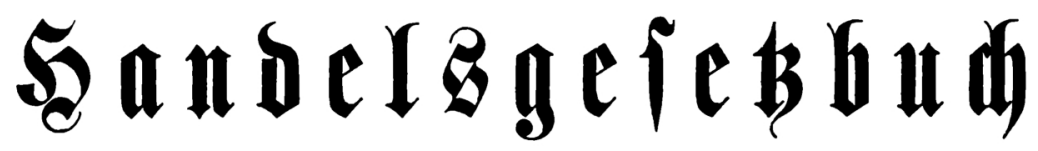

\section{mit Rommentar}

heraugegeben von

f. $\mathfrak{A l} \mathfrak{a} k \mathfrak{o} \mathfrak{m} \mathfrak{e r}$.

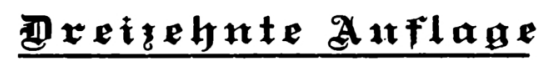

bearbeitet bon

5. Mtakomer, Redtłananalt.

$\mathfrak{G r f t e r} \mathfrak{e}^{\mathfrak{a} a \mathfrak{d} \boldsymbol{d} .}$

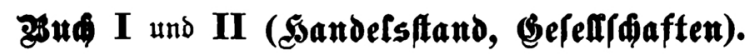

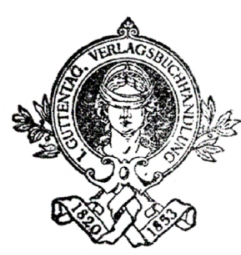

Berlin 1906.

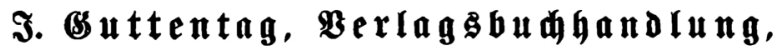
B. m. 6. . 
